\title{
A systemic review of Toxic Death in clinical oncology trials: an Achilles' heel in safety reporting revisited
}

\author{
B Penninckx, , WM Van de Voorde ${ }^{2}$, A Casado ${ }^{3}$, N Reed $^{4}$, C Moulin $^{5}$ and M Karrasch' \\ 'Medical Department, EORTC Headquarters, E. Mounierlaan 83/II, 1200 Brussels, Belgium; ${ }^{2}$ Forensic Medicine Department, University Hospitals \\ Leuven, Kapucijnenvoer 33, 3000 Leuven, Belgium; ${ }^{3}$ Department of Medical Oncology, Hospital Universitario San Carlos, C/Prof. Martin Lagos, 28040 \\ Madrid, Spain; ${ }^{4}$ Beatson Oncology Centre, Gartnavel General Hospital, 1053 Great Western Road, Glasgow, Scotland GI2 OYN, UK; ${ }^{5}$ Fellowship \\ Programme Unit, EORTC Headquarters, E. Mounierlaan 83/II, 1200 Brussels, Belgium
}

BACKGROUND: Toxic death is defined as study treatment-related mortality and as such is considered as an iatrogenic death. This belongs to unnatural death where an autopsy is advised. Until now, conventional autopsy is the gold standard to discriminate between pre- and post-mortem discrepancies.

METHODS: The consequences of lack of systematically performing an autopsy will be explored in the setting of oncological clinical trials. RESULTS: During more than one decade, 6428 Serious Adverse Events have been registered in the EORTC Safety database on a total of 34734 subjects. The number of deaths were 764 (mortality rate of $2.2 \%$ ) whereof 255 (rate of $0.7 \%$ ) toxic deaths. In $89.8 \%$ of these toxic deaths, no autopsy has been done; in 25.1\% (64 cases) an inconsistent cause of death was found based on studying of the medical narrative. The autopsy rate was only $10.2 \%$ (26 out of 255 ) and, in $46.2 \%$ of the performed autopsies, there was a clinical pathological discrepancy.

CONCLUSION: When no autopsy is performed, there is a high risk for a wrong diagnosis in case of suspected toxic death. The high discrepancy rate, possibly due to a low autopsy rate, shows that toxic death is an Achilles' heel in iatrogenic mortality.

British Journal of Cancer (2012) 107, I-6. doi:I0.1038/bjc.2012.252 www.bjcancer.com

Published online 7 June 2012

(C) 2012 Cancer Research UK

Keywords: autopsy; EORTC; oncological trial; toxic death

Toxic death is far from being a common understanding in the medical world. It has been used over many decades in oncology and, more specifically, in oncological clinical trials. The reason is that, historically, and still today, a substantial proportion of the subjects die in these studies. Main reasons for this mortality are the disease itself and nocive effects of the therapies which are often the last possible treatment options in a cancer population. Roberts et al (2004) defined 'Toxic Death' as treatment-related death, specified as fatal toxicity due to trial participation. One can define toxic death as a fatal Serious Adverse Event (SAE) related to study treatment.

As such, toxic death falls under the denominator of iatrogenic death (unnatural cause) and has to be distinguished from mortality due to the disease (natural death) itself. This brings toxic death in the domain of forensic medicine, where an autopsy could be necessary to give a definitive answer on the cause of death (Saukko and Knight, 2004; Madea and Saukko, 2008; Van de Voorde, 2010). When autopsy is mentioned throughout the text, referral is made to forensic or medicolegal autopsy.

The conduct of a clinical trial in Europe is regulated by Clinical Trial Directives and a major part of this legislation is the legal translation of the guidelines on Good Clinical Practice (GCP). Despite these directives, which include procedures when a subject dies in a clinical trial, the obligation to perform an autopsy for final diagnosis is missing. To note is the huge variation of autopsy rates in the world ranging from 4 to $49 \%$ (Saukko and Pollak, 2000).

*Correspondence: Dr B Penninckx; E-mail: doublebjorn@hotmail.com Received I6 January 2012; revised 4 May 2012; accepted II May 2012; published online 7 June 2012
In parallel there is a European Recommendation with criteria for performing a medicolegal autopsy, which applies to unexpected and unnatural deaths (Anonymous, 2000). However, iatrogenic death and as such toxic death is not specifically mentioned in this document.

Conventional autopsy as an instrument to reveal diagnostic discrepancies has been empirically proven throughout the years with first publications since 1912 (Shojania et al, 2003; Roulson et al, 2005). The classification of discrepancies between pre- and post-mortem findings according to Goldman can be considered as the reference (Goldman et al, 1983; Battle et al, 1987).

The goal of this work is to highlight the problems that may arise from lack of a correct diagnostic approach when a subject dies in an oncological clinical trial.

\section{MATERIALS AND METHODS}

\section{Database}

The SAE from a series of oncological clinical trials conducted within the European Organisation for Research and Treatment of Cancer (EORTC) is stored in a safety database, called SAfE (on site acronym for SAE Database). These clinical trials have been carried out with ethical committee approvals.

\section{Assessment of data}

Data extraction has been performed by one author (BP) for the period of 01 January 1999 until 28 January 2011 for the total number of SAE, deaths, and toxic deaths. In case of 
Table I Goldman classification for clinical pathological discrepancies

\begin{tabular}{lll}
\hline Discrepancy & Class & Description \\
\hline Major & Class I & $\begin{array}{l}\text { Missed diagnoses with potential adverse impact on } \\
\text { survival and detection before death would have } \\
\text { probably changed the treatment decisions } \\
\text { Missed diagnoses with no potential impact on survival } \\
\text { when management would have changed }\end{array}$ \\
Minor & Class II III & $\begin{array}{l}\text { Missed diagnoses related to the terminal disease but } \\
\text { not related to the cause of death }\end{array}$ \\
Class IV & $\begin{array}{l}\text { Missed diagnoses not related to terminal disease or } \\
\text { cause of death }\end{array}$ \\
assessable & $\begin{array}{l}\text { No satisfactory diagnoses are found clinically or on } \\
\text { the autopsy report to explain the cause of death }\end{array}$ \\
\hline
\end{tabular}

classification as toxic death, additional information is collected from the pharmacovigilance narrative and an autopsy report request is done, as standard procedure.

A first analysis was done independently by two authors (MK and BP): When an autopsy was performed, then the clinical-pathological diagnostic discrepancy was assessed using the criteria from Goldman (Goldman et al, 1983). These criteria are shown in Table 1. Furthermore, the clinical reported cause of death diagnosis was reviewed to check its consistency in relation to the pharmacovigilance narrative. As such, we classified the cause of death diagnosis as consistent or inconsistent (and/or undetermined) in relation to the pharmacovigilance narrative. When no autopsy was performed, or no information of such autopsy was available, only the latter consistency review was done. For all the cases, the diagnostic term accuracy was verified using the Preferred Term of the Medical Dictionary for Regulatory Activities (MedDRA) terminology.

The further classification was done according to the country where the SAE was experienced; type of oncological disease; gender, and age category $(<18,18-45,45-65, \geqslant 65)$. The amount of recruited subjects in the concerned studies for the same time period was extracted from the clinical database.

The corresponding author had complete access to the data in these studies and takes full responsibility for data integrity and correctness of its analyses.

An important remark is that most of the study protocols have exemption rules for SAE. The most important is presumed disease progression, described earlier (Roberts et al, 2004). Presumed disease progression would as such not appear in the safety database, although it can be a potential toxic death.

\section{Statistical methods}

No formal statistics was used and the analyses of the data were purely descriptive.

\section{RESULTS}

During more than one decade, 6428 SAE were registered within SAfE. These SAE were reported from 92 clinical trials. The number of deaths was 764 cases (mortality rate of $2.2 \%$ ) whereof 255 (rate of $0.7 \%$ ) toxic deaths and 509 cases of non-treatment related deaths. To put these numbers in relation to recruitment and geographical distribution, the accrual numbers during the same period are displayed in the graphs below (Figure $1 \mathrm{~A}$ and $\mathrm{B}$ ). Worthwhile to mention, the recruitment number of 34734 subjects in these 92 studies was approximately half of the total accrual number of EORTC subjects (67003) during that period (data from the EORTC Annual report 2011-2012). The reason is that only studies were taken into account with reported deaths and where EORTC is the owner of the safety database.

\section{Clinical versus post-mortem diagnosis}

In the majority of the 255 study treatment-related deaths, no autopsy was performed, that is, 229 cases (89.8\%). From these 229 deaths without autopsy, the reported cause of death was undetermined and/or inconsistent with the described narrative in 64 cases (25.1\% from toxic deaths). An autopsy was only done in a minority of the cases ( 26 cases or $10.2 \%$ ), and within 12 of these (46.2\% of the autopsies), there was a clinical-pathological discrepancy. One case could not be assessed because of the fact that the cause of death remained uncertain after autopsy. To note is that autopsy in this case was limited to macroscopy only without any histo-pathological examination. This is summarised in Table 2.

\section{Potential consequence of not systematically performing an autopsy}

Despite the fact that in 8 of the 12 autopsies, the clinical diagnosis was consistent with the narrative, discrepant post-mortem findings were discovered. When we extrapolate this to the 165 toxic deaths without autopsy and a cause of death diagnosis consistent with the narrative, there is a potential wrong cause of death reported in 110 cases. Adding the 64 cases with an inconsistent or undetermined cause of death, the risk for a wrong cause of death diagnosis increases to $68.2 \%$ (174 out of 255 cases) from the toxic deaths due to negligence of performing an autopsy.

Details about the 12 clinical-pathological discrepancies are displayed in Table 3. All these cases had major discrepancies, and in 7 cases $(26.9 \%$ of the autopsies), a Class I discrepancy was withheld.

\section{Geographical spread}

The median accrual in these 92 studies was 1465 subjects (min-max: 5-9214) with 4 studies where more than 1000 subjects were recruited. When the safety data were analysed in relation to accrual and geographical origin, the following could be noted. The rate of toxic death on all deaths was almost constant (33.4\%) in the different countries, with an exception for Spain where this rate was much lower with 3 toxic deaths for 31 mortalities $(9.7 \%)$ on a total of 1816 recruited subjects. The cause of death diagnosis was inconsistent with the narratives in France in half of the toxic deaths. The above is described in Table 4. Eastern European countries tend to underreport SAE as can be seen from Figure 1.

\section{Tumour disease type}

A subdivision according to oncological disease type has been done in Table 5. Most of the mortalities and toxic deaths were seen in leukaemia trials with, respectively, 192 cases and 94 cases. There was a huge variance $(3.8-100.0 \%)$ of the toxic deaths in relation to the deaths among the different disease groups.

\section{Demographic data}

The division of the data according to gender and age category is represented in Table 6 . There was no distinction between the two sexes related to number of autopsies performed. A low number of autopsies were observed within subjects younger than 45 years old.

\section{DISCUSSION}

\section{Autopsy advocacy}

Our manuscript is built upon the assumption that autopsy is the gold standard for correct diagnosis definition, but how far is that true? Published data mention that a technically and adequately performed conventional autopsy fails to determine the correct 

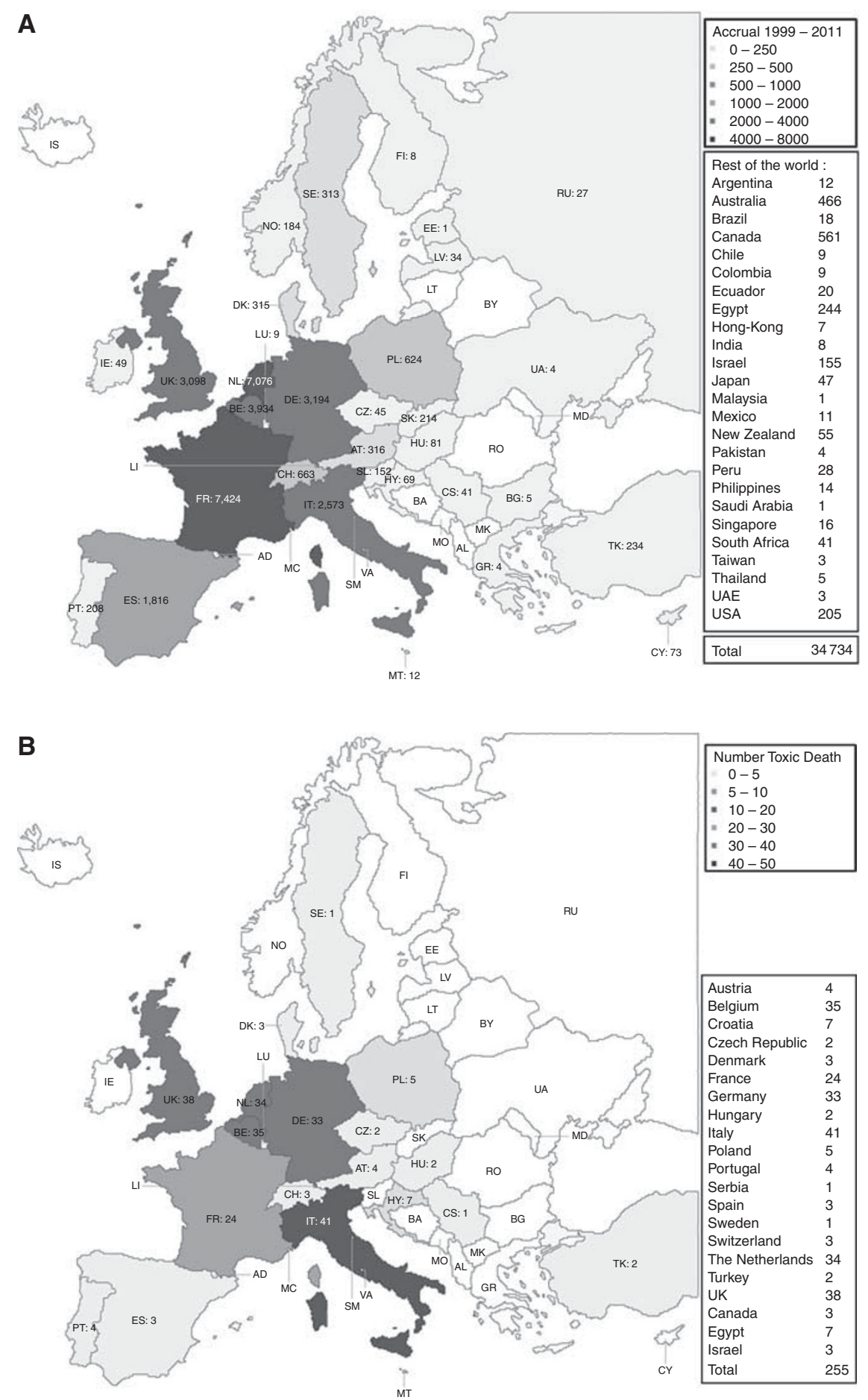

Figure I (A) Recruitment density from 92 EORTC studies between 1999 and 20 I I. (B) Toxic death density from 92 EORTC studies between 1999 and 2011 .

cause of death in $1-7 \%$ of the cases (Rilke, 1991; Shojania et al, 2003; Van de Voorde, 2010). On the opposite, when no autopsy has been performed, data shows a wrong cause of death diagnosis in about $30 \%$ of the cases (Pritt et al, 2005; Cambridge and Cina, 2010). The diagnostic problems for fatal sepsis, multi-organ failure, and systemic inflammatory response syndrome are highlighted in a recent publication (Pastores et al, 2007). Addition of a few biomarkers could ameliorate the diagnostic value of autopsy in case of sepsis (Tsokos, 2007). Another problem with toxic death could be interpretation difficulties from post-mortem toxicological results, such as inter-individual differences in metabolisation of drugs (Musshoff et al, 2010; Sajantila et al, 2010).

In our study, the cause of death remained undetermined in one case, probably owing to the fact that the autopsy did not include a microscopical investigation. Not only the correct diagnosis is important but as well the causal relationship with study treatment. In clinical trials where efficacy and safety from study treatment is investigated, it is paramount to know whether the mortality was 
Table 2 Toxic death in relation to autopsy status and diagnosis at death

\begin{tabular}{lccc}
\hline 255 toxic deaths (764 & deaths) & Number & \% toxic death \\
\hline Autopsy performed & Concordant $^{\mathrm{a}}$ & 13 & 5.1 \\
& Discrepant $^{\mathrm{a}}$ & 12 & 4.7 \\
& Not Assessable $^{\mathrm{a}}$ & $\mathrm{I}$ & 0.4 \\
\multirow{2}{*}{ No autopsy performed } & Consistent $^{\mathrm{b}}$ & 165 & 64.7 \\
& Inconsistent $^{\mathrm{b}}$ & 64 & 25.1 \\
\hline
\end{tabular}

${ }^{a}$ Diagnostic discrepancy between pre- and post-mortem findings according to Goldman. ${ }^{b}$ Relation between clinical cause of death diagnosis and medical case narrative (Inconsistent includes undetermined cause of death diagnosis).

Table 3 Classification from twelve discrepant cases between pre- and post-mortem findings according to Goldman

\begin{tabular}{lll}
\hline Case & Clinical diagnosis & Autopsy findings \\
\hline Class I (missed primary diagnoses with a potential impact on survival and treatment \\
strategy) \\
I & Veno-occlusive disease of liver & Candidia albicans sepsis \\
2 & Escherichia coli sepsis & Aspergillus pneumopathy \\
3 & Aspergillus infection & Bacterial sepsis \\
4 & Opportunistic bacterial infection & Disseminated fungal infection \\
5 & Cerebral toxoplasmosis & Cerebral fungal infection \\
6 & Death of unknown cause & Pulmonary edema/ Pneumonia/ \\
7 & Pneumonia & Abdominal venostasis \\
& & Deep venous thrombosis and \\
Class II (missed primary diagnoses without impact on survival and treatment strategy) \\
8 & Chemotherapy hepatoxicity & Pulmonary aspergillosis \\
9 & Mycotic brain abcess & Haemorrhagic left brain damage \\
I0 & Fungal pneumonia & Non-fungal bronchopneumonia \\
II & Bleomycin-induced pneumopathy & CMV pneumonia \\
& or Pneumocystosis & \\
I2 & Pancytopenia & Sepsis \\
\hline
\end{tabular}

Table 4 Toxic death in relation to its geographic origin

\begin{tabular}{|c|c|c|c|c|c|c|}
\hline \multirow[b]{2}{*}{ Country } & \multirow[b]{2}{*}{$\begin{array}{c}\text { Mortality } \\
\text { number } \\
\text { (rate \%) }\end{array}$} & \multicolumn{2}{|c|}{ Toxic death } & \multirow[b]{2}{*}{$\begin{array}{l}\text { Autopsy } \\
\text { number }\end{array}$} & \multicolumn{2}{|c|}{ No autopsy } \\
\hline & & $\begin{array}{l}\text { Number } \\
\text { (rate \%) }\end{array}$ & $\begin{array}{c}\% \text { of } \\
\text { mortality }\end{array}$ & & Cons. & Incons. \\
\hline Austria & $15(4.7)$ & $4(1.3)$ & 26.7 & 2 & 2 & \\
\hline Belgium & $126(3.2)$ & $35(0.9)$ & 27.8 & 3 & 23 & 9 \\
\hline Canada & $11(1.4)$ & $3(0.4)$ & 27.3 & & 3 & \\
\hline East-Europe $^{\mathrm{a}}$ & $32(2.5)$ & $17(1.3)$ & 53.1 & 3 & 11 & 3 \\
\hline France & $80(1.1)$ & $24(0.3)$ & 30.0 & i & 12 & 11 \\
\hline Germany & $120(3.8)$ & $33(1.0)$ & 27.5 & & 26 & 7 \\
\hline Italy & $82(3.2)$ & $41(1.6)$ & 50.0 & 7 & 27 & 7 \\
\hline Portugal & $7(3.4)$ & $4(1.9)$ & 57.1 & & 3 & i \\
\hline RoW $^{\text {g }}$ & $41(3.4)$ & $10(0.8)$ & 24.4 & & 5 & 5 \\
\hline Scandinavia ${ }^{c}$ & $12(1.5)$ & $4(0.5)$ & 33.3 & 1 & 3 & \\
\hline Spain & $31(1.7)$ & $3(0.2)$ & 9.7 & & 2 & 1 \\
\hline Switzerland & $10(1.5)$ & $3(0.5)$ & 30.0 & & 2 & 1 \\
\hline The Netherlands & $102(1.4)$ & $34(0.5)$ & 33.3 & 7 & 21 & 6 \\
\hline Turkey & $7(1.8)$ & $2(0.5)$ & 28.6 & & I & I \\
\hline UK & $88(2.8)$ & $38(1.2)$ & 43.2 & 2 & 24 & 12 \\
\hline Total & $764(2.2)$ & $255(0.7)$ & 33.4 & 26 & 165 & 64 \\
\hline
\end{tabular}

Abbreviations: Cons./Incons. = Consistent/Inconsistent cause of death diagnosis compared with the medical narrative. ${ }^{2}$ East Europe: Bulgaria, Croatia, Czech Republic

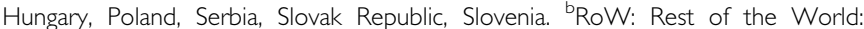
Argentina, Australia, Brazil, Ecuador, Egypt, Hong-Kong, India, Israel, Japan, Pakistan, Peru, Russia, South Africa, Taiwan. 'Scandinavia: Denmark, Norway, Sweden

due to study treatment or could be attributed to another reason. Autopsy is still unbeaten in both excluding and confirming the causal relationship with drugs (Ebbesen et al, 2001; Madea et al, 2009; Madea and Preuss, 2009).
Table 5 Toxic death in relation to oncological disease group

\begin{tabular}{|c|c|c|c|c|c|c|}
\hline \multirow{2}{*}{$\begin{array}{l}\text { Disease group } \\
\text { (Number } \\
\text { of subjects) }\end{array}$} & \multirow[b]{2}{*}{$\begin{array}{l}\text { Mortality } \\
\text { number }\end{array}$} & \multicolumn{2}{|c|}{ Toxic death } & \multirow[b]{2}{*}{$\begin{array}{l}\text { Autopsy } \\
\text { number }\end{array}$} & \multicolumn{2}{|c|}{ No autopsy } \\
\hline & & Number & $\begin{array}{c}\% \text { of } \\
\text { mortality }\end{array}$ & & Cons. & Incons. \\
\hline $\begin{array}{l}\text { Chronotherapy } \\
\text { (199) }\end{array}$ & 6 & 3 & 50.0 & । & । & । \\
\hline Leukaemia (I023) & 192 & 94 & 49.0 & 11 & 66 & 17 \\
\hline Lung ( 1442$)$ & 34 & 21 & 61.8 & 2 & 13 & 6 \\
\hline Breast (I I 996) & 41 & 12 & 29.3 & & 6 & 6 \\
\hline $\operatorname{NDD}(430)$ & 53 & 2 & 3.8 & 1 & & I \\
\hline Melanoma (2823) & 83 & 10 & 12.0 & & 8 & 2 \\
\hline Lymphoma (2904) & 37 & 29 & 78.4 & 5 & 16 & 8 \\
\hline $\begin{array}{l}\text { Cutaneous } \\
\text { lymphoma (49) }\end{array}$ & 4 & 3 & 75.0 & & I & 2 \\
\hline $\begin{array}{l}\text { Radiation oncology } \\
(2609)\end{array}$ & 23 & 3 & 13.0 & 1 & & 2 \\
\hline $\begin{array}{l}\text { Head and neck } \\
(178)\end{array}$ & 5 & 4 & 80.0 & & 2 & 2 \\
\hline Brain (1 |66) & 19 & 5 & 26.3 & 1 & 3 & 1 \\
\hline $\begin{array}{l}\text { Genito-urinary } \\
(2221)\end{array}$ & 83 & 23 & 27.7 & I & 16 & 6 \\
\hline $\begin{array}{l}\text { Gastro-intestinal } \\
\text { (1 | } 92 \text { ) }\end{array}$ & 22 & 10 & 45.5 & & 9 & I \\
\hline $\begin{array}{l}\text { Gynaecology } \\
(2875)\end{array}$ & 29 & 12 & 41.4 & I & 7 & 4 \\
\hline $\begin{array}{l}\text { Children's } \\
\text { leukaemia (25) }\end{array}$ & 2 & 2 & 100.0 & & 2 & \\
\hline $\begin{array}{l}\text { STBS (2907) } \\
\text { Infectious diseases } \\
(628)\end{array}$ & $\begin{array}{l}59 \\
65\end{array}$ & 21 & 35.6 & 2 & 15 & 4 \\
\hline $\mathrm{NOCl}(76)$ & 7 & I & 14.3 & & & । \\
\hline Total (34 743) & 764 & 255 & 33.4 & 26 & 165 & 64 \\
\hline
\end{tabular}

Abbreviations: $\mathrm{NDD}=$ new drug development; $\mathrm{STBS}=$ soft tissue and bone sarcoma; $\mathrm{NOCl}=$ Network Of Core Institutions; Cons./Incons. = Consistent/Inconsistent cause of death diagnosis compared with the medical narrative

Table 6 Toxic death in relation to gender and age category

\begin{tabular}{|c|c|c|c|c|c|}
\hline \multirow[b]{2}{*}{ Gender } & \multirow[b]{2}{*}{$\begin{array}{c}\text { Mortality } \\
\text { number }\end{array}$} & \multirow[b]{2}{*}{$\begin{array}{l}\text { Toxic death } \\
\text { number }\end{array}$} & \multirow[b]{2}{*}{$\begin{array}{l}\text { Autopsy } \\
\text { number }\end{array}$} & \multicolumn{2}{|c|}{ No autopsy } \\
\hline & & & & Cons. & Incons. \\
\hline Male & 461 & 143 & 15 & 91 & 37 \\
\hline Female & 303 & 112 & 11 & 74 & 27 \\
\hline \multicolumn{6}{|l|}{ Age category } \\
\hline$<18$ year & 2 & 2 & & 2 & \\
\hline 1 8-45 year & 97 & 18 & 3 & || & 4 \\
\hline 45-65 year & 293 & 95 & 16 & 55 & 24 \\
\hline$\geqslant 65$ year & 372 & 140 & 7 & 97 & 36 \\
\hline
\end{tabular}

Abbreviations: Cons./Incons. = Consistent/inconsistent cause of death diagnosis compared with the medical narrative.

Until today, other techniques such as minimally invasive (needle biopsy and endoscopic) and non-invasive (post-mortem total body CT or MRI) autopsies have not been widely accepted to replace conventional autopsy (Ermenc, 2000; Bisset et al, 2002; Burton and Underwood, 2007; Thomsen et al, 2009; Fan et al, 2010; Roberts et al, 2012).

\section{Mortality and toxic death rate}

This study reveals a mortality rate of $2.2 \%$ and a toxic death rate of $0.7 \%$ (34 734 subjects) that can be considered, respectively, at the lower limit and upper limit compared with data in the literature for mortality rate $(2.1-20.2 \%)$ and toxic death rate $(0.1-0.95 \%)$ (Lazarou et al, 1998: Ebbesen et al, 2001; Roberts et al, 2004; Pastores et al, 2007). To place toxic death rate in perspective, in one study they found that fatal SAE are double as high compared with the number of fatal traffic accidents (Madea and Preuss, 
2009). In another study, fatal SAE counted for between the fourth and sixth cause of death in US hospitals (Lazarou et al, 1998).

The extreme mortality number of $20.2 \%$ (658 deaths on 3257 patients) in one study can be explained by the fact that this was observed in an oncological intensive ward (Pastores et al, 2007). Our study deals with an oncological population with an inherent increased risk for dying. However our mortality rate is on the lower end. This can only be partially explained by underreporting of the number of SAE, such as in a Swedish study where they mentioned that $86 \%$ of adverse events are not reported (Backstrom et al, 2004). In most of the EORTC trials, monitoring is foreseen and possible non-reported cases would have been detected. A more plausible explanation could be that, in a lot of trial protocols, cancer progression is excluded to be reported as an SAE. Consequently, when such subject dies, disease progression may not be the cause of death and a potential toxic death as such is not reported. Another explanation is selection bias, because according to GCP guidelines, it is the investigator's responsibility to assess the causal relationship between death and study treatment. Some investigators have the tendency to declare the death preferentially due to the disease or its complications (Pastores et al, 2007; Burgesser et al, 2011). Without an autopsy, it is far from evident to declare a case as study treatment related mortality or not. Thus, in our study with 509 cases reported as non-treatment-related death, an unknown percentage, in fact, could be a treatment-related mortality.

\section{Autopsy rate and diagnostic discrepancy}

It is important to learn from ante-mortem errors, but also to know whether the death is due to study treatment or not (Rilke, 1991; Madea and Preuss, 2009; Lehrnbecher et al, 2010). Probably one out of three death certificates are wrong in the absence of autopsy (Roulson et al, 2005).

The autopsy rate in this analysis was $10.2 \%$ (26 out of 255 ). In the literature, this varied from $3.7 \%$ to $100 \%$ (Goldman et al, 1983; Battle et al, 1987; Saukko and Pollak, 2000; Ebbesen et al, 2001; Shojania et al, 2003; Roulson et al, 2005; Aalten et al, 2006; Burton and Underwood, 2007; Pastores et al, 2007; Shojania and Burton, 2008; Van de Voorde, 2010), the most recent data (last 20 years) ranging between $3.7 \%$ and $28.4 \%$ (Shojania et al, 2003; Roulson et al, 2005; Aalten et al, 2006; Burton and Underwood, 2007; Shojania and Burton, 2008). One exception is the prospective study from Ebbesen with an autopsy rate of $78.1 \%$ (Ebbesen et al, 2001). This is interesting as the goal of this study was to look at incident rates of toxic deaths in the hospital. Accordingly, our autopsy rate is low in determining pre- and post-mortem discrepancies.

Moreover, we found in our study a diagnostic discrepancy rate of $46.2 \%$ (in 12 autopsies on a total of 26 autopsies or $4.7 \%$ from the toxic deaths). All these discrepancies were major, whereof Class I discrepancies compromised $26.9 \%$ of the autopsies. Published data varies between $23.5 \%$ and $39.0 \%$ for major discrepancies and from 9.0 to $25.5 \%$ for Class I discrepancies (Goldman et al, 1983; Battle et al, 1987; Di et al, 1991; Shojania et al, 2003; Roulson et al, 2005; Aalten et al, 2006; Pastores et al, 2007; Burgesser et al, 2011). The high rates both for major and Class I discrepancies are not so surprising as they are correlated with low autopsy rates. It has been shown that major and Class I discrepancies decrease with, respectively, $12.4 \%$ and $17.4 \%$ for each increase of autopsy rate by $10 \%$ (Shojania et al, 2003; Van de Voorde, 2010).

Most of the discrepancies in this study were fungal infections (mainly pulmonary) followed by sepsis and thromboembolic events. In the study from Burgesser et al (2011), these were mainly respiratory infections and acute myocardial infarction. The author stated that $15 \%$ from the cases were transplantation patients and with the use of immunosuppressive drugs, making them more susceptible for infections. This is also the case in an oncological population where a lot of bone marrow suppressive agents make these patients vulnerable for infections. Embolic events in cancer patients are not exceptional, because the tumour and therapy are both risk factors for developing emboli. Lung emboli and opportunistic infections (viral, bacterial and fungal) are often a source of clinical-pathological discrepancy in the literature (Goldman et al, 1983; Battle et al, 1987; Rilke, 1991; Roulson et al, 2005; Aalten et al, 2006; Pastores et al, 2007; Lehrnbecher et al, 2010; Burgesser et al, 2011).

\section{Geographical differences}

In most countries, the number of toxic deaths was approximately one-third of the mortality numbers, except for Spain where this was only $9.7 \%$. We cannot explain this effect, because these studies were run internationally and the same monitoring was applied among these countries. We did not observe higher autopsy rates in contrary of what is described in literature for regions such as the USA, Canada, UK, Hungary, Sweden and Switzerland (Burton and Underwood, 2007; Van de Voorde, 2010). In these countries no or only a few autopsies were performed despite the quite high recruitment numbers.

In $25.1 \%$ of the toxic deaths, the cause of death diagnosis was inconsistent with the narrative, and no autopsy was performed to verify the correct diagnosis. The reason for, in France, this even happened in half of the cases, remains unclear. It is certainly not the only country with a low autopsy rate, but autopsy could have helped to decrease the inconsistency rate.

\section{Tumour and demographic characteristics}

A high mortality and toxic death rate were reported for leukaemia trials. A possible explanation for this effect is that the majority of the subjects were older patients with acute myeloid leukaemia and as such represented a black and white matrix compared with nonhaematological tumours. Together with a highly toxic therapy resulting in a lot of infectious complications, it may not be surprising that this disease is still characterised with a high mortality. The high variance of the toxic death rate among the different tumour types was remarkable and probably due to the high heterogeneity of the population and its treatment strategy.

An interesting observation was the low number of autopsies within subjects younger than 45 years old. In forensic medicine, dying at young age and iatrogenic death (including toxic death) are considered unnatural deaths and autopsy is advised. Despite the presence of both conditions, it did not result in a higher autopsy rate for this subpopulation.

\section{Shortcomings of this study}

Firstly this is a retrospective study that generates bias for available information. It is possible that only when there was doubt about the clinical cause of death diagnosis, an autopsy was performed.

Some of these deaths may have occurred at home or in smaller district hospitals where the investigator has little chance to influence requesting an autopsy.

Most of autopsy rates in publications are based on hospitalised cohorts and not as in this study where both subjects in ambulant and hospital environment were included. Cautious comparison is therefore needed with these publications.

At last, the safety database is constructed in such way to report to regulatory bodies. The disadvantage is that in case there is no relationship between death and study treatment, available information is very limited. Only when a death is classified as toxic death (by the investigator), a narrative is generated and stored in the database, and completed with an autopsy report when 
available. It may not be a surprise that, even with consideration of the results of the study here, this is a potential source of bias.

\section{CONCLUSION}

This study with 34734 subjects recruited during more than one decade in 92 oncological studies has a mortality rate of $2.2 \%$ and a toxic death rate of $0.7 \%$. The low autopsy rate of $10.2 \%$ (26 autopsies on 255 toxic deaths) severely disrupts the quality and correctness of the diagnoses, translating in a high diagnostic discrepancy rate of $46.2 \%$ (or $4.7 \%$ of all toxic deaths). The majority of diagnostic discrepancies were fungal infections, which were discovered by autopsy. Because of negligence of performing an autopsy, the risk for a wrong cause of death diagnosis peaks at $68.2 \%$. It is justified to systematically perform an autopsy in case of suspected toxic death, not only for the value of autopsy as a diagnostic test, but also to identify similar cases with a Class I

\section{REFERENCES}

Aalten CM, Samson MM, Jansen PA (2006) Diagnostic errors; the need to have autopsies. Neth J Med 64(6): 186-190

Anonymous (2000) Recommendation no. R (99) 3 of the Committee of Ministers to member states on the harmonization of medico-legal autopsy rules. Forensic Sci Int 111(1-3): 5-58

Backstrom M, Mjorndal T, Dahlqvist R (2004) Under-reporting of serious adverse drug reactions in Sweden. Pharmacoepidemiol Drug Saf 13(7): 483-487

Battle RM, Pathak D, Humble CG, Key CR, Vanatta PR, Hill RB, Anderson RE (1987) Factors influencing discrepancies between premortem and postmortem diagnoses. JAMA 258(3): 339-344

Bisset RA, Thomas NB, Turnbull IW, Lee S (2002) Postmortem examinations using magnetic resonance imaging: four year review of a working service. BMJ 324(7351): 1423-1424

Burgesser MV, Camps D, Calafat P, Diller A (2011) Discrepancies between clinical diagnoses and autopsy findings. Medicina (B Aires) 71(2): 135-138

Burton JL, Underwood J (2007) Clinical, educational, and epidemiological value of autopsy. Lancet 369(9571): 1471-1480

Cambridge B, Cina SJ (2010) The accuracy of death certificate completion in a suburban community. Am J Forensic Med Pathol 31(3): 232-235

Di FL, Piga A, Marmili S, Breccia R, Rubini C, Beltrami CA, Mariuzzi GM, Cellerino R (1991) The value of necropsy in oncology. Eur J Cancer 27(5): 559-561

Ebbesen J, Buajordet I, Erikssen J, Brors O, Hilberg T, Svaar H, Sandvik L (2001) Drug-related deaths in a department of internal medicine. Arch Intern Med 161(19): 2317-2323

Ermenc B (2000) Comparison of the clinical and post mortem diagnoses of the causes of death. Forensic Sci Int 114(2): 117-119

Fan JK, Tong DK, Poon JT, Lo OS, Beh PS, Patil NG, Law WL (2010) Multimodality minimally invasive autopsy - a feasible and accurate approach to post-mortem examination. Forensic Sci Int 195(1-3): 93-98

Goldman L, Sayson R, Robbins S, Cohn LH, Bettmann M, Weisberg M (1983) The value of the autopsy in three medical eras. $N$ Engl J Med 308(17): 1000-1005

Lazarou J, Pomeranz BH, Corey PN (1998) Incidence of adverse drug reactions in hospitalized patients: a meta-analysis of prospective studies. JAMA 279(15): 1200-1205

Lehrnbecher T, Frank C, Engels K, Kriener S, Groll AH, Schwabe D (2010) Trends in the postmortem epidemiology of invasive fungal infections at a university hospital. J Infect 61(3): 259-265

Madea B, Musshoff F, Preuss J (2009) Medical negligence in drug associated deaths. Forensic Sci Int 190(1-3): 67-73 discrepancy and where correct ante-mortem knowledge might have influenced the survival. This paper should serve as a stimulus for further investigation in this matter and as a recommendation to perform an autopsy at a higher percentage of death events in clinical trials.

\section{ACKNOWLEDGEMENTS}

We would like to thank Thomas Valkaerts for query programming to extract data from the SAfE. This publication was supported by Fonds Cancer (FOCA) from Belgium.

\section{Conflict of interest}

The authors declare no conflict of interest.
Madea B, Preuss J (2009) Medical malpractice as reflected by the forensic evaluation of 4450 autopsies. Forensic Sci Int 190(1-3): 58-66

Madea B, Saukko P (2008) Forensic medicine in Europe. SchmidtRoemhild: Lubeck

Musshoff F, Stamer UM, Madea B (2010) Pharmacogenetics and forensic toxicology. Forensic Sci Int 203(1-3): 53-62

Pastores SM, Dulu A, Voigt L, Raoof N, Alicea M, Halpern NA (2007) Premortem clinical diagnoses and postmortem autopsy findings: discrepancies in critically ill cancer patients. Crit Care 11(2): R48

Pritt BS, Hardin NJ, Richmond JA, Shapiro SL (2005) Death certification errors at an academic institution. Arch Pathol Lab Med 129(11): 1476-1479

Rilke F (1991) The autopsy: its role in oncology. Eur J Cancer 27(5): 528-530

Roberts IS, Benamore RE, Benbow EW, Lee SH, Harris JN, Jackson A, Mallett S, Patankar T, Peebles C, Roobottom C, Traill ZC (2012) Postmortem imaging as an alternative to autopsy in the diagnosis of adult deaths: a validation study. Lancet 379(9811): 136-142

Roberts Jr. TG, Goulart BH, Squitieri L, Stallings SC, Halpern EF, Chabner BA, Gazelle GS, Finkelstein SN, Clark JW (2004) Trends in the risks and benefits to patients with cancer participating in phase 1 clinical trials. JAMA 292(17): 2130-2140

Roulson J, Benbow EW, Hasleton PS (2005) Discrepancies between clinical and autopsy diagnosis and the value of post mortem histology; a metaanalysis and review. Histopathology 47(6): 551-559

Sajantila A, Palo JU, Ojanpera I, Davis C, Budowle B (2010) Pharmacogenetics in medico-legal context. Forensic Sci Int 203(1-3): 44-52

Saukko P, Pollak S (2000) Postmortem Examination, Procedures and Standards. In Encyclopedia of Forensic Sciences, Jay AS (ed), pp 1272-1275. Elsevier: Oxford

Saukko PJ, Knight B (2004) Knight's forensic pathology. 3rd edn. Arnold: London

Shojania KG, Burton EC (2008) The vanishing nonforensic autopsy. N Engl $J$ Med 358(9): 873-875

Shojania KG, Burton EC, McDonald KM, Goldman L (2003) Changes in rates of autopsy-detected diagnostic errors over time: a systematic review. JAMA 289(21): 2849-2856

Thomsen AH, Jurik AG, Uhrenholt L, Vesterby A (2009) An alternative approach to computerized tomography (CT) in forensic pathology. Forensic Sci Int 183(1-3): 87-90

Tsokos M (2007) Postmortem diagnosis of sepsis. Forensic Sci Int 165(2-3): $155-164$

Van de Voorde W (2010) Handboek Forensische Geneeskunde. 1st edn. Die Keure

This work is published under the standard license to publish agreement. After 12 months the work will become freely available and the license terms will switch to a Creative Commons Attribution-NonCommercial-Share Alike 3.0 Unported License. 